\title{
Mycotoxic fungi, mycotoxins, mycotoxicoses: an encyclopedic handbook
}

Edited by T. D. WyLle and L. G. Morehouse. 1977. Vol. 1: Mycotoxic fungi and chemistry of mycotoxins. New York and Basel: Marcel Dekker, Inc. Pp. xxiv and 538.

If the standards of Volume 1 are maintained in Volume 2, which is entitled " Mycotoxicoses of domestic and laboratory animals, poultry and aquatic invertebrates and vertebrates ", and in Volume 3, entitled "Mycotoxicoses of men and plants: mycotoxin control and regulatory practices", a valuable encyclopaedic handbook will have been produced. It is clear that the editors have not only selected their authors with great care, but carefully briefed them on what each chapter should contain.

In 1961, the recognition that Turkey $\mathrm{X}$ disease was due to aflatoxin, by Allcroft and Carnaghan of the Central Veterinary Laboratory (CVL), Weybridge, and Sargant and O'Kelly of the Tropical Products Institute (TPI), London, heralded a new era of international research into mycotoxins. It is, therefore, noteworthy that the authoritative chapters on the chemistry of aflatoxin and related compounds are not only by two senior workers at the CVL and TPI, but comprise one-fifth of this volume. The international authorship includes eleven authors from America, three from the United Kingdom, three from New Zealand, and one each from Canada, Finland, Israel and South Africa, reflecting the special interests and experience of the workers of these countries.

The first 128 pages are devoted to the identification of genera and selected species of mycotoxin-producing fungi. The key to the genera is clear and the line drawings are excellent. In the sections on individual fungal genera, however, a few of the photomicrographs are not of the standard one expects in a modern encyclopaedia and this is also true of the drawings for the genus Fusarium. The author of this chapter, in reducing Fusarium tricinctum to a variety of $F$. sporotrichioides, uncritically departs from the current classification based on the sporogenous cells, as described in the widely accepted monograph of Booth. The suggestion that the taxonomy of Fusarium spp. may have been a subject of purely academic interest is somewhat dated, as Fusarium spp. are probably the most important of the soilborne phytopathogens and have been widely recognised as such since the pioneering studies of Erwin F. Smith in 1899.

The frontispiece shows scanning electronmicrographs of four fungi, and their order, reading from upper left clockwise, is logical, but I found it confusing because I had difficulty in recognising the conidiospores of Pithomyces chartarum; the hyaline collar is shown and there is an obvious transverse septation, but very little visible ornamentation of the walls. The photomicrograph on p. 100, on the other hand, shows the roughening of the wall, and longitudinal as well as transverse septation, and is therefore a greater aid to identification.

This volume will prove a very welcome addition not only to the libraries, but to the laboratories of many workers. With laboratory use in mind, production is marred by the poor quality of the binding. The paper-covered boards seem to be too heavy for the spine, and after one reading for the purposes of this review, the book was already beginning to come apart.

R. R. Davies

\section{Salmonella}

Report by a Study Group of the British Association for the Advancement of Science. 1978. London: Brit. Ass. Adv. Sci. Pp. i and 51. £1.00.

Although written in layman's language, this publication presents a useful review of salmonellosis in the British Isles. Salmonellosis in man is considered briefly and a more extensive coverage would have been appropriate. There is inadequate appraisal of institutional outbreaks in which cross-infection is the most common mode of spread; hospital outbreaks deserve particular study because the current situation leaves no room for complacency. The report gives a balanced and comprehensive assessment of salmonellosis in food-producing animals and discusses in detail the problems of the farmer. There is a useful chapter on the legislative measures that are concerned with the veterinary aspects, but 